\title{
BMJ Open Education, job position, income or multidimensional indices? Associations between different socioeconomic status indicators and chronic low back pain in a German sample: a longitudinal field study
}

\author{
Michael Fliesser, Jessie De Witt Huberts, Pia-Maria Wippert
}

To cite: Fliesser M, De Witt Huberts J, Wippert P-M. Education, job position, income or multidimensional indices? Associations between different socioeconomic status indicators and chronic low back pain in a German sample: a longitudinal field study. BMJ Open 2018;8:e20207. doi:10.1136/ bmjopen-2017-020207

- Prepublication history for this paper is available online To view these files, please visit the journal online (http://dx.doi org/10.1136/bmjopen-2017020207).

Received 24 October 2017 Revised 22 February 2018 Accepted 9 April 2018
Check for updates

Department of Health and Physical Activity, Sociology of Health and Physical Activity, University of Potsdam, Potsdam, Germany

Correspondence to

Michael Fliesser;

fliesser@uni-potsdam.de

\section{ABSTRACT}

Objective To investigate associations between

socioeconomic status (SES) indicators (education, job position, income, multidimensional index) and the genesis of chronic low back pain (CLBP).

Design Longitudinal field study (baseline and 6-month follow-up).

Setting Four medical clinics across Germany.

Participants 352 people were included according to the following criteria: (1) between 18 and 65 years of age, (2) intermittent pain and (3) an understanding of the study and the ability to answer a questionnaire without help. Exclusion criteria were: (1) pregnancy, (2) inability to stand upright, (3) inability to give sick leave information, (4) signs of serious spinal pathology, (5) acute pain in the past 7 days or (6) an incomplete SES indicators questionnaire. Outcome measures Subjective intensity and disability of CLBP.

Results Analysis showed that job position was the best single predictor of CLBP intensity, followed by a multidimensional index. Education and income had no significant association with intensity. Subjective disability was best predicted by job position, succeeded by the multidimensional index and education, while income again had no significant association.

Conclusion The results showed that SES indicators have different strong associations with the genesis of CLBP and should therefore not be used interchangeably. Job position was found to be the single most important indicator.

These results could be helpful in the planning of back pain care programmes, but in general, more research on the relationship between SES and health outcomes is needed.

\section{BACKGROUND}

In the health sciences, it is widely accepted that socioeconomic status (SES) is linked to many health outcomes. ${ }^{1}$ However, less is known about the causal pathways and mediating factors that lead to these outcomes. This gap in research is partially caused by unresolved methodological issues concerning the
Strengths and limitations of this study

- Analysis of different socioeconomic status (SES) indicators and their influence on the genesis of chronic low back pain.

- This comparison was driven by various regression models within the same sample to highlight variations in CLBP prediction when using different SES indicators.

- Limitations include a small and homogeneous sample of above-average SES status and the use of only the most common SES indicators, the setting in one country and the focus on one health domain.

- Transferability has to be proven in other health settings and countries.

operationalisation of SES. Because SES is a latent construct, various indicators can be used to measure a person's SES. The most commonly used indicators are education, job position and income, or combinations of these variables. ${ }^{2}$ The justification for specific SES indicator use is often not adequately described in articles, ${ }^{3}$ and some SES indicators are even used interchangeably. ${ }^{4}$ This limits the interpretation of results because different indicators are based on different theoretical models connecting SES indicators to health outcomes. For example, job position is strongly connected with stress which then detrimentally influences health. Whereas education is strongly associated with knowledge about health and treatments. ${ }^{5}$ It thus becomes obvious that the chosen indicator will indeed influence the association with specific health outcomes. This has already been confirmed for several health outcomes, including myocardial infarction, ${ }^{6}$ overall mortality, ${ }^{67}$ diabetes ${ }^{6}$ and subjective 
health status. ${ }^{89}$ After reviewing these studies, two things become noteworthy. First, each SES indicator differs in its connection with specific health outcomes which leads to the notion that SES indicators should initially be analysed separately for each health domain of interest. Second, in the studies investigating links between SES and health outcomes, it was rarely acknowledged that different indicators led to different results, nor discussed why. ${ }^{3}$ For a better understanding of the relationship between SES and health, improved methodology yielding more information concerning indicator associations and underlying mechanisms is needed. Therefore, the objective of this study was to compare and report the association of common SES indicators with the genesis of one common global health problem, chronic low back pain (CLBP).

CLBP seems a suitable health outcome to investigate regarding its connection to SES. It is a major public health burden with an international lifetime prevalence of approximately $39 \%$, whereby about $20 \%$ of people suffer from CLBP. ${ }^{10}$ Moreover, the development of chronic pain has a multidimensional aetiology and is moderated by health behaviour, ${ }^{11}$ as well as social ${ }^{12}$ and psychological factors. ${ }^{13}$ For these reasons, we hypothesise that different SES indicators will lead to different degrees of association in the genesis of CBLP. However, past studies analysing CLBP and SES have used a variety of different SES indicators, often without explanation. ${ }^{3}$ To date, only one study from Latza et al has compared different SES indicators and their relative influence on self-reported back pain. They found education to have the strongest association with chronic back pain, followed by job position and income. ${ }^{14}$ However, and this is crucial, they did not use identical samples for all SES prediction calculations. So, it is not clear whether the observed differences were caused by the SES indicators or by differences in the samples. Hence, a study investigating the link between different SES indicators and CLBP in a single sample is needed.

Before evaluating, it is important to have a differentiated perspective on factors mediating the relationship between SES and health. ${ }^{5}$ According to the well-established model of social determinants of health by Brunner and Marmot ${ }^{15}$ there are three groups of factors mediating SES and health: material factors (eg, pollution), social and psychological factors (eg, stress) and health behaviour (eg, dietary habits). Translating this general model to the current example, prior research has revealed that CLBP is most strongly associated with social and psychological factors, such as depressive symptoms, ${ }^{16}$ stress $^{17}$ and dissatisfaction with work organisation. ${ }^{18}$ Health behaviour has also been associated with CLBP, ${ }^{19}{ }^{20}$ however material factors have not. Based on these findings, it could be assumed that SES indicators more closely associated with social/psychological factors and health behaviour will have stronger associations with CLBP. Hradil, examining the influence of SES indicators on cardiovascular diseases, assumed job position to be most strongly connected with social and psychological factors, education with health behaviour and income with material factors. ${ }^{5}$ Using these assumptions, we hypothesise that the single indicator, job position will be strongly associated with the genesis of CLBP, followed by education. Income, we believe, will have the weakest association. The multidimensional index, covering all possible pathways, should however yield the strongest association.

\section{METHOD}

Sample

Participants were recruited from four medical clinics across Germany as part of a national study on low back pain (National Research Network for Medicine in Spine Exercise, MiSpEx $\left.{ }^{21}\right)$. Inclusion criteria consisted of: (1) 18-65 years of age, (2) intermittent pain, (3) an understanding of the study and the ability to answer a questionnaire without help. Exclusion criteria were (1) pregnancy, (2) inability to stand upright, (3) inability to give sick leave information or (4) signs of serious spinal pathology. This led to a primary sample size of $n=1071$ participants. To ensure homogeneity and to avoid bias, only participants, who at the time of assessment were actually employed and answered all relevant SES indicator questions, were included. This reduced the sample size to $n=654$. Furthermore, as SES association with the genesis of CLBP is the focus, participants already reporting serious chronic pain syndromes at baseline were excluded, reducing the sample to $n=367$ participants. After final screening, an insufficient number of some SES groups (primary and lower-secondary educational level, agricultural workers, machine operators and elementary occupations) was observed (under 10 people in each group), therefore these groups were excluded from further analysis, leading to a final sample size of $n=352$.

\section{Testing procedure}

All measurements were performed in the four medical clinics of the MiSpEx Network. Participants completed questionnaires regarding SES and CLBP at baseline and again 6 months later. Written consent was obtained from all participants. The study was in accordance with the principles of the Declaration of Helsinki.

\section{Patient and public involvement}

The participants were informed that the study was about LBP. They were not involved in the development of the design, recruitment or study conduction. Each participant got an individual feedback of his or her results shortly after the study was finished.

\section{Instruments and data preprocessing}

SES indicators

SES was evaluated at baseline using the following instruments:

Education was assessed using the International Standard Classification of Education (ISCED) which combines school and vocational education, ${ }^{22}$ resulting in a score 
from 0 (less than primary education) to 5 (tertiary education).

Job position was measured using the 10 major categories from the International Standard Classification of Occupation 08 , combining jobs according to main tasks, skill level and specialisation. ${ }^{23}$

Monthly net personal income was separated into seven brackets $(<€ 1250, € 1250-€ 1749, € 1750-€ 2249$, €2250$€ 2999, € 3000-€ 3999, € 4000-€ 4999, \geq € 5000)$ based on the recommendations of the German Federal Statistical Institute and grouped at the extremes. ${ }^{24}$

Multidimensional SES index was calculated using the Winkler-Scheuch Index (WS-index). This index, a revised version of the German Working Group for Social Epidemiology recommendations, ${ }^{25}$ is based on three dimensions: education (a combination of general and job-specific educational level obtained together with ISCED), job position (a combination of position and qualification) and income. The composition is similar to those of international additive indices, for example, Hollighead's 'Index of Social Status'. ${ }^{26}$ Participants were scored between 1 and 7 for each of the single indicators. The total of these three values then determined the participant's WS-index score. ${ }^{25}$

\section{Pain indicators}

Pain intensity was evaluated using the Chronic Pain Grade (CPG) questionnaire created by von Korff $e t a l^{27}$ which inquires the current intensity of pain, the average intensity of pain in the last 3 months and the worst experienced pain in the last 3 months. Possible answers range from 0 (no pain) to 10 (worst pain possible). The mean of these three questions was calculated and multiplied by 10 , resulting in a score of $0-100$ for each participant. These variables were collected at baseline and at follow-up 6 months later. Internal consistency was good at both measurement points (baseline: Cronbach's $\alpha=0.76$; follow-up: Cronbach's $\alpha=0.82$ ).

Pain disability was evaluated using three questions from the CPG questionnaire concerning how much pain interfered with daily, recreational, social and work activities (again rated on a scale from 0 to 10 ). The mean of these three questions was calculated and the result multiplied by 10 , resulting in a score from 0 to $100 .^{27}$ Internal consistency was excellent at both measurement points (baseline: Cronbach's $\alpha=0.87$; follow-up: Cronbach's $\alpha=0.93)$.

Pain class: to exclude participants with current strong or disabling CLBP, a pain classification index was used at baseline (CPG pain classes). This scale grades pain intensity, pain disability and the number of days with limitations due to pain into five classes: 0 , no pain; 1 , pain with low intensity and low disability; 2 , pain with low disability but high intensity; 3, pain with high disability with few days of limitation in everyday life; 4 , pain with high disability with severe limitation in everyday life. ${ }^{27}$ For the present study, only participants from pain classes 0 and 1 at baseline were included.

\section{Statistical analysis}

After descriptive statistics calculation, four separate hierarchical regression analyses were conducted for each pain outcome using either education, job position, monthly personal net income or the multidimensional index as the respective predictors, while controlling for age and sex. These two variables are known for their high predictive value in the development of back pain. ${ }^{28}$ Education, job position and income thereby were treated as dummy variables to reflect the categorical character of these variables. As most studies only use one indicator to represent SES, a separate model for each indicator was used here as this allowed for comparisons in variability if the other indicators had not been taken into account. Requirements of the regression analysis were tested with collinearity diagnosis, Durbin-Watson test and Kolmogorov-Smirnov test for normality of residuals. All analyses were performed with IBM SPSS Statistics V.21.

\section{RESULTS}

\section{Descriptive statistics}

Sample characteristics (tables 1 and 2) revealed $55 \%$ of respondents were women, and on average, the sample was middle-aged, but ranging from 19 to 65 years. Generally, participants were highly educated and held high job positions. Mean monthly net personal income was between $€ 1750$ and $€ 2249$, while the average WS-index score was 14.9 on the scale from 3 to 21. CLBP intensity and disability were low at both baseline and 6-month follow-up.

People with primary or lower secondary education, agricultural workers, machine operators and elementary job positions are excluded from further analysis because of the small sample size in the groups.

\section{Regression models}

Regarding pain intensity (table 3), only 'job position' and 'WS-index' significantly improved variance explanation. Comparing variance explanation of respective SES indicators, the ranking was as follows: job position (change in $R^{2}=0.04, \mathrm{p}<0.01$ ), WS-index (change in $R^{2}=0.02, \mathrm{p}<0.05$ ), education (change in $R^{2}=0.02$, not significant) and income (change in $R^{2}=0.01$, not significant). Further, analysis revealed that people with upper secondary education reported, on average, greater pain intensity compared with people with tertiary education. Considering job position, technicians had significantly lower pain intensity scores compared with managers. Income did not contribute to variance explanation, nor were there any significant differences between income brackets. The multidimensional WS-index (included as a continuous variable) improved the model significantly to confirm people with higher overall SES reported less back pain.

Pain disability models yielded different results (table 4). Education, job position and WS-index explained a significant amount of variance, even sharing a stronger association in comparison with pain intensity. The strongest 
Table 1 Sample characteristics (categorical variables, $n=367$ )

\begin{tabular}{|c|c|c|c|c|c|}
\hline Variable & $\mathbf{n}$ & $\%$ & & $\mathbf{n}$ & $\%$ \\
\hline Education & & & Job position & & \\
\hline Primary education & 4 & 1.1 & Managers & 34 & 9.2 \\
\hline Upper secondary education & 105 & 28.5 & Technicians & 124 & 34.0 \\
\hline Postsecondary-non-tertiary education & 80 & 21.7 & Clerical support workers & 37 & 10.1 \\
\hline Income & & & Agricultural workers & 1 & 0.3 \\
\hline Under €1250 & 60 & 16.3 & Craft workers & 16 & 4.3 \\
\hline$€ 1250-€ 1749$ & 74 & 20.4 & Machine operators & 3 & 0.8 \\
\hline$€ 1750-€ 2249$ & 59 & 16.0 & Elementary occupations & 5 & 1.4 \\
\hline$€ 2250-€ 2999$ & 56 & 15.2 & & & \\
\hline More than $€ 5000$ & 25 & 6.8 & & & \\
\hline
\end{tabular}

predictor was job position (change in $R^{2}=0.07, \mathrm{p}<0.01$ ), followed by WS-index (change in $R^{2}=0.05, \mathrm{p}<0.01$ ), then education (change in $R^{2}=0.02, \mathrm{p}<0.05$ ). Income had no significant association with disability. People with professional and secondary education were significantly more disabled due to back pain than people with tertiary education. Professionals reported, in comparison with managers, significantly less impairment, while craft workers reported significantly more. Although the income model did not improve variance explanation, people with an income of less than $€ 1250$ reported significantly more impairment than people earning over $€ 5000$. People with a higher general SES (indicated by the multidimensional index) reported fewer limitations due to back pain.

\section{DISCUSSION}

The purpose of this study was to report and compare the association of common SES indicators with the genesis of CLBP. Differences between these indicators were found, suggesting that SES indicators should be selected very carefully to avoid underestimation of SES's influence on CLBP. Our results show job position is the strongest predictor and should always be appraised in further research regarding CLBP. In contrast, income and education were determined to be suboptimal predictors of CLBP. In this respect, the current findings differ from studies in other health domains. For example, Geyer et $a t^{6}$ found education to be a much stronger predictor of diabetes than job position, and income was a better predictor of overall mortality compared with education and job position. Miech and Hauser ${ }^{8}$ determined education to better predict subjective health than occupation which was not corroborated by Geyer, ${ }^{9}$ who found income and job position to be superior. Again, this just illustrates the consequences of SES operationalisation and the importance of considering all possible pathways connecting SES indicators and distinct health outcomes.

In line with our hypothesis, we confirmed the single indicator, job position and the multidimensional index to be the most influential predictors of CLBP intensity. In detail, technicians reported significantly less CLBP intensity compared with managers. We believe this could be due to technicians' greater coping opportunities, but

Table 2 Sample characteristics (continuous variables, $n=367$ )

\begin{tabular}{lcccc}
\hline Variable (range) & Mean & SD & Min & Max \\
\hline Age (18-65) & 41.0 & 11.8 & 19 & 65 \\
Winkler-Scheuch Index (3-21) & 14.9 & 2.9 & 13.8 & 0.4 \\
CPG pain intensity baseline (0-100) & 21.0 & 16.7 & 0 & 47 \\
CPG pain intensity follow-up (0-100) & 19.4 & 12.7 & 0 & 67 \\
CPG disability baseline (0-100) & 9.9 & 15.6 & 0 & 63 \\
CPG disability follow-up (0-100) & 9.7 & 0.3 & 0 & 90 \\
CPG pain class baseline & 0.9 & 1 \\
\hline
\end{tabular}

CPG, Chronic Pain Grade questionnaire. 
Table 3 Four hierarchical regression models of different operationalisations predicting influence of SES on CPG pain intensity score (higher values more pain)

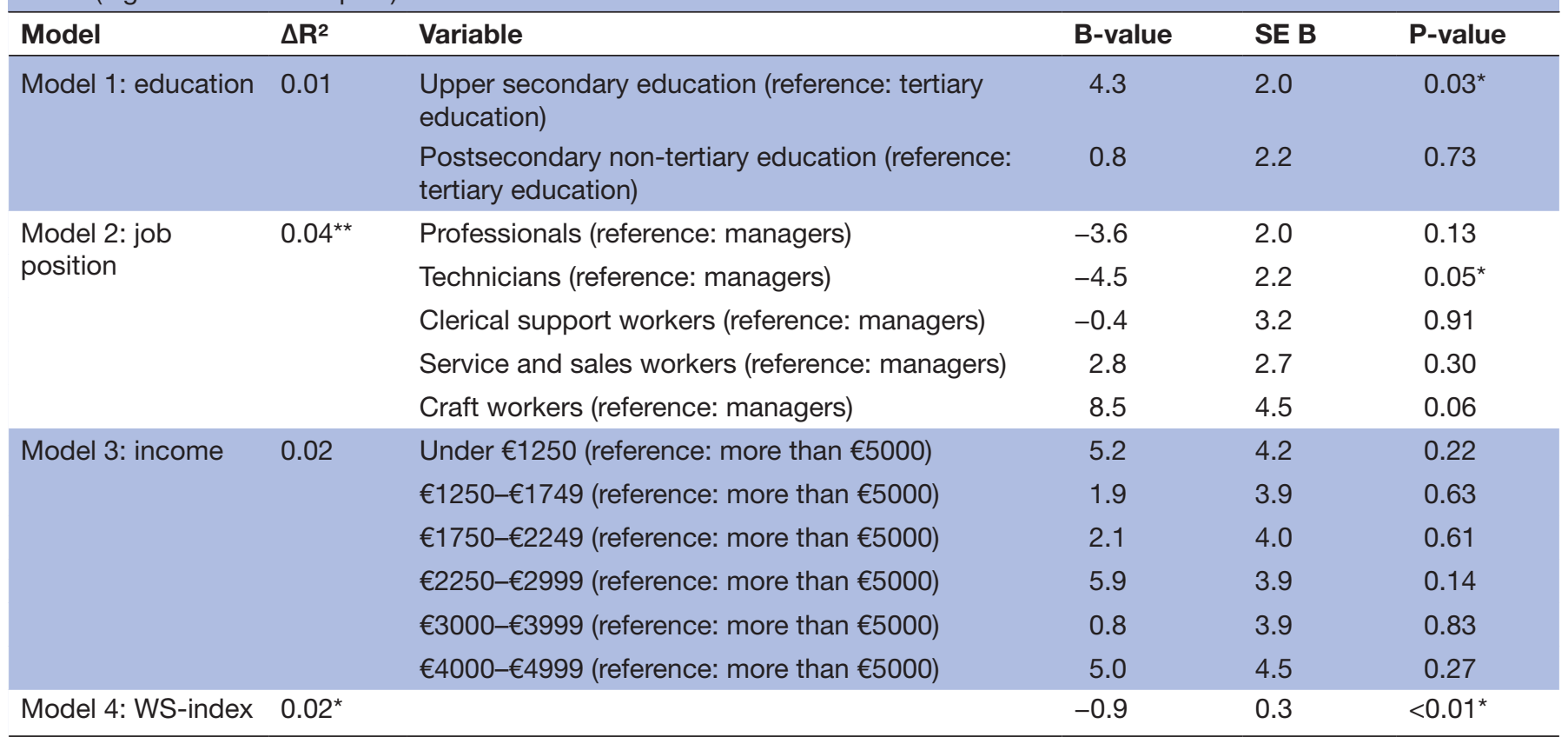

Controlled for age and sex $(n=352) . \Delta R^{2}$ indicates model improvement after application of SES indicator.

${ }^{*} \mathrm{P}<0.05$; ${ }^{*} \mathrm{P}<0.01$.

CPG, Chronic Pain Grade questionnaire; SES, socioeconomic status; WS-index, Winkler-Scheuch Index.

further research should be designed to answer such questions. Income showed no significant associations and was not a reliable predictor for CLBP intensity. Education, also, did not explain variance, although people with upper secondary education did experience significantly more pain than people with tertiary education. Previous

Table 4 Four hierarchical regression models of different operationalisations predicting influence of SES on CPG pain disability score

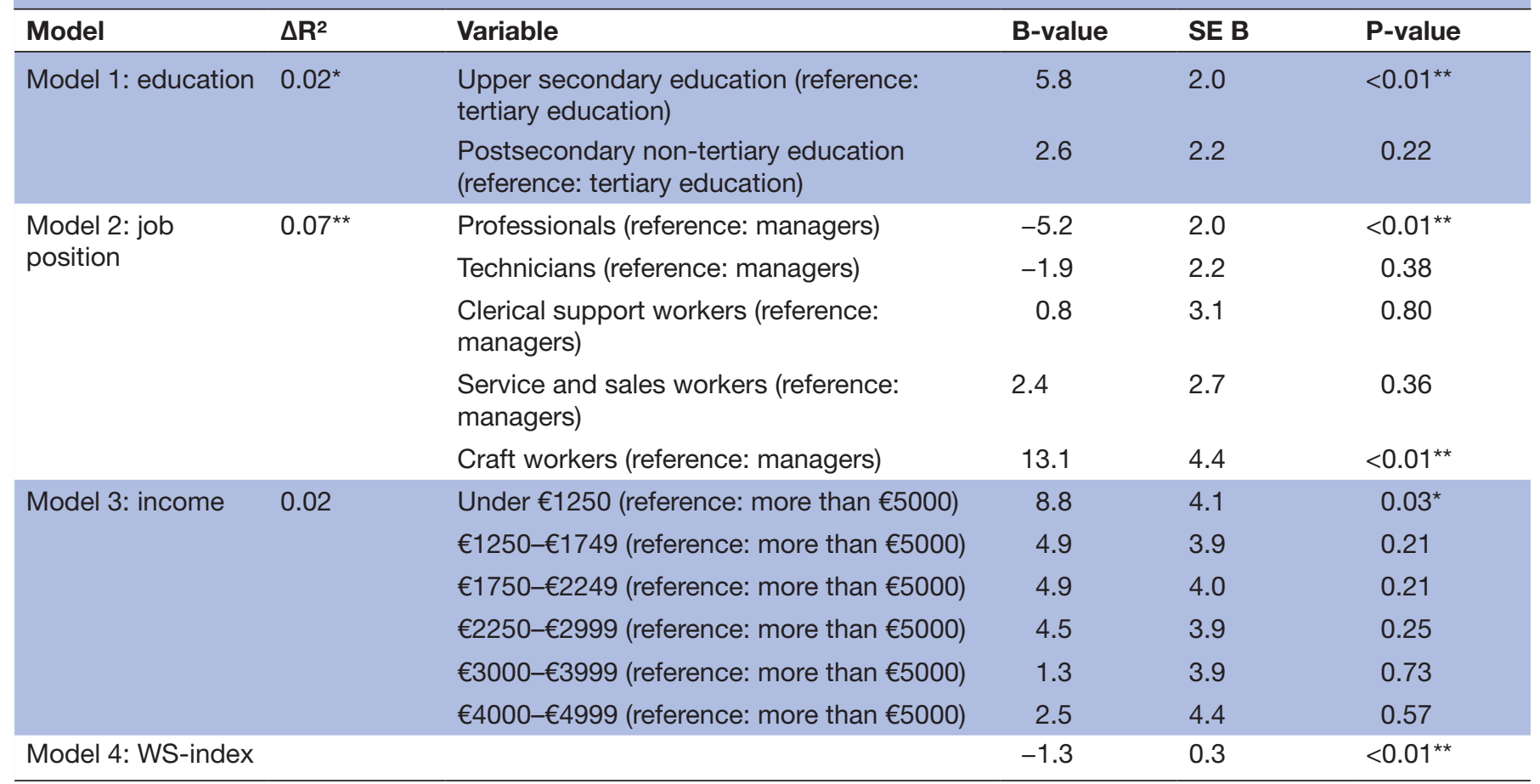

Controlled for age and $\operatorname{sex}(\mathrm{n}=352) . \Delta R^{2}$ indicates model improvement after application of SES indicator. ${ }^{*} \mathrm{P}<0.05$; ${ }^{* *} \mathrm{P}<0.01$.

CPG, Chronic Pain Grade questionnaire; SES, socioeconomic status; WS-index, Winkler-Scheuch Index. 
studies have explained such findings to be influenced by better knowledge concerning healthy and preventative behaviour. ${ }^{5}$ We reasonable assumed that the WS-index would yield a significantly stronger association than the single indicators; yet, this was not the case. Clearly, the addition of single SES dimensions does not necessarily deliver a cumulative increase in the association, which was also found to be the case by Geyer, ${ }^{9}$ although in a different health domain. The overlapping of indicators and mediating factors is potentially the problem here, leading to a shared influence on CLBP for all indicators or effects of one indicator being counterbalanced by another.

Focusing on associations between SES and CLBP disability, our results were again partly in agreement with our hypotheses. Job position was, as expected, the most influential single predictor. Professionals reported significantly less impairment due to CLBP compared with managers, while craft workers reported more. In similar vein as the intensity results, we believe professionals have better possibilities to adjust their work environments when experiencing CLBP, something neither managers nor craft workers are afforded. The multidimensional index explained the second most variance in CLBP disability. Again, we found it is wrong to assume the associations of single dimensions will sum up. Education was also a significant predictor of CLBP disability, but not to the degree of job position or WS-index. Similarly, to intensity, upper secondary educated people reported greater impairment compared with tertiary educated people. Income could not significantly explain any variance, although people in the lowest income bracket reported greater impairment in comparison with those from the highest. Higher incomes may enable these people to acquire certain material resources, which could reduce their disability in everyday life.

To our knowledge, this is the first study to compare the association of various SES indicators with CLBP in a single sample. Our results confirm SES indicators should be selected carefully and not used interchangeably. In our study, the pathways described in the model of Brunner and Marmot ${ }^{15}$ were used to predict associations between various SES indicators and CLBP. Our findings did however contradict some of these predictions emphasising just how difficult it is to predict a priori, the most appropriate SES indicators.

The results presented in this paper are afflicted by some limitations, namely the small group sizes of primary and lower secondary educated people, agricultural workers, machine operators and elementary occupations which led to the exclusion of these groups. This reduces the explanatory power of the results and may produce an underestimation in the predicted association of education and job position. A replication study including more people from lower education and job groups would assure more conclusive and generalisable results. Furthermore, the lowest income bracket was relatively broad. We speculate income may have had a stronger association, had this category been split up. The study was also conducted in four study centres in Germany. Although Germany has comparable numbers to other European countries regarding pain prevalence and severity rates, ${ }^{29}$ country-specific differences may lead to conflicting results in other countries. Additionally, not all approaches to gauge SES were taken into account. Newer approaches, for example, self-assessed socioeconomic status ${ }^{30}$ or neighbourhood indicators, ${ }^{3}$ could improve future studies, but as of yet, no statement can be made as to whether these approaches would have influenced our results. In this study, income was evaluated as personal net income, but perhaps the material situation of some would be better reflected by household income which may hide some heterogeneity.

In conclusion, this study highlighted job position as an all-important dimension concerning SES's association with CLBP. Further research aiming to prevent and reduce CLBP should therefore focus on conditions that may be influenced by job positions.

Acknowledgements Thanks go to the network principal investigator, Frank Mayer, and researchers of the MiSpEx network, namely Adamantios Arampatzis, Marcus Schiltenwolf, Heidrun Beck, who were involved in the planning and conducting of the multicentre study. We thank further MiSpEx colleagues, Winfried Banzer, Christian Schneider, Karsten Dreinhöfer, Nikolaus Streich, Philipp Kasten, Petra Platen, and many others. We thank both the technical and medical staff at our study clinics for their investment during the study's conduction. We further thank Michael Rector for valuable support through linguistic innovations and suggestions. We further acknowledge the support in the publication process of the Deutsche Forschungsgemeinschaft and Open Access Publishing Fund of University of Potsdam.

Contributors All authors substantially contributed to the conception and realisation of this article. MF conceived and wrote the first draft of this manuscript and provided statistical analysis. JDWH and P-MW revised the manuscript. P-MW was responsible for the psychometric design, analysis plan and conceived the social methods of the multicentre study. All authors read and approved the final manuscript.

Funding This study is funded by the German Federal Institute of Sport Science on behalf of the Federal Ministry of the Interior of Germany. It is conducted within MiSpEx-the National Research Network for Medicine in Spine Exercise (grantnumber: 080102A/11-14).

Competing interests None declared.

Patient consent Not required.

Ethics approval The study was approved by the Independent Ethics Committee of University of Potsdam (Ethics approval 36/2011).

Provenance and peer review Not commissioned; externally peer reviewed.

Data sharing statement No additional data available.

Open Access This is an Open Access article distributed in accordance with the Creative Commons Attribution Non Commercial (CC BY-NC 4.0) license, which permits others to distribute, remix, adapt, build upon this work non-commercially, and license their derivative works on different terms, provided the original work is properly cited and the use is non-commercial. See: http://creativecommons.org/ licenses/by-nc/4.0/

(C) Article author(s) (or their employer(s) unless otherwise stated in the text of the article) 2018. All rights reserved. No commercial use is permitted unless otherwise expressly granted.

\section{REFERENCES}

1. Braveman PA, Cubbin C, Egerter S, et al. Socioeconomic status in health research: one size does not fit all. JAMA 2005;294:2879-88. 
2. Nocon M, Keil T, Willich SN. Education, income, occupational status and health risk behaviour. J Public Health 2007;15:401-5.

3. Fliesser M, Klipker K, Wippert P-M. Zur Verwendung des sozioökonomischen Status in der Gesundheitsforschung am Beispie Rückenschmerz - systematisches Review. Gesundheitswesen 2016.

4. Cundiff JM, Uchino BN, Smith TW, et al. Socioeconomic status and health: education and income are independent and joint predictors of ambulatory blood pressure. J Behav Med 2015;38:9-16.

5. Hradil S. Was prägt das Krankheitsrisiko- Schicht, Lage, Lebensstil? In: Richter M, Hurrelmann K, eds. Gesundheitliche Ungleichheit: Grundlagen, Probleme, Perspektiven. 2nd edn.. Wiesbaden: VS, Verl. für Sozialwiss, 2009:33-52.

6. Geyer S, Hemström O, Peter R, et al. Education, income, and occupational class cannot be used interchangeably in social epidemiology. Empirical evidence against a common practice. $J$ Epidemiol Community Health 2006;60:804-10.

7. Stringhini S, Dugravot A, Kivimaki M, et al. Do different measures of early life socioeconomic circumstances predict adult mortality? Evidence from the British Whitehall II and French GAZEL studies. J Epidemiol Community Health 2011;65:1097-103.

8. Miech RA, Hauser RM. Socioeconomic status and health at midlife. A comparison of educational attainment with occupation-based indicators. Ann Epidemiol 2001;11:75-84.

9. Geyer S. Einzelindikator oder Index? Maße sozialer Differenzierung im Vergleich. Gesundheitswesen 2008;70:281-8.

10. Hoy D, Bain C, Williams $\mathrm{G}$, et al. A systematic review of the global prevalence of low back pain. Arthritis Rheum 2012;64:2028-37.

11. van Hecke $\mathrm{O}$, Torrance $\mathrm{N}$, Smith $\mathrm{BH}$. Chronic pain epidemiology where do lifestyle factors fit in? Br J Pain 2013;7:209-17.

12. Goldberg DS, McGee SJ. Pain as a global public health priority. BMC Public Health 2011;11:770.

13. van Hecke $\mathrm{O}$, Torrance $\mathrm{N}$, Smith $\mathrm{BH}$. Chronic pain epidemiology and its clinical relevance. Br J Anaesth 2013;111:13-18.

14. Latza U, Kohlmann T, Deck R, et al. Influence of occupational factors on the relation between socioeconomic status and self-reported back pain in a population-based sample of German adults with back pain. Spine 2000;25:1390-7.

15. Brunner G, Marmot MG. Social organisation, stress, and health. In: Marmot MG, Wilkinson RG, eds. Social determinants of health. 2nd edn. Oxford, New York: Oxford University Press, 2011:6-30.

16. Bair MJ, Robinson RL, Katon W, et al. Depression and pain comorbidity: a literature review. Arch Intern Med 2003;163:2433-45.

17. Hoy D, Brooks P, Blyth F, et al. The epidemiology of low back pain. Best Pract Res Clin Rheumatol 2010;24:769-81.
18. Chou $\mathrm{R}$, Shekelle $\mathrm{P}$. Will this patient develop persistent disabling low back pain? JAMA 2010;303:1295-302.

19. Brox JI, Storheim K, Holm I, et al. Disability, pain, psychological factors and physical performance in healthy controls, patients with sub-acute and chronic low back pain: a case-control study. J Rehabil Med 2005;37:95-9.

20. Melloh M, Elfering A, Egli Presland C, et al. Identification of prognostic factors for chronicity in patients with low back pain: a review of screening instruments. Int Orthop 2009;33:301-13.

21. Wippert PM, Puschmann AK, Drießlein D, et al. Development of a risk stratification and prevention index for stratified care in chronic low back pain. Focus: yellow flags (MiSpEx network). Pain Rep 2017;2:e623.

22. UNESCO. International standard classification of education: ISCED 2011. Montreal, Quebec: UNESCO Institute for Statistics, 2012.

23. Statistik Austria. ISCO 08- gemeinsame deutschsprachige Titel und Erläuterungen. 2011 http://www.statistik.at/wcm/idc/idcplg? IdcService=GET PDF FILE\&dDocName $=049974$

24. Destatis. Demografische standards. 2017 https://www.destatis.de/ DE/Methoden/DemografischeRegionaleStandards/DemografischeSt andardsInfo.html.

25. Lampert T, Kroll LE, Müters S, et al. Messung des sozioökonomischen Status in der Studie „Gesundheit in Deutschland aktuell" (GEDA). Bundesgesundheitsblatt Gesundheitsforschung Gesundheitsschutz 2013;56:131-43.

26. Hollinghead AB. Four factor index of social status. Yale Journal of Sociology 2011;8:21-52.

27. Von Korff M, Ormel J, Keefe FJ, et al. Grading the severity of chronic pain. Pain 1992:50:133-49.

28. de Schepper El, Damen J, van Meurs JB, et al. The association between lumbar disc degeneration and low back pain: the influence of age, gender, and individual radiographic features. Spine 2010;35:531-6.

29. Breivik H, Collett B, Ventafridda V, et al. Survey of chronic pain in Europe: prevalence, impact on daily life, and treatment. European Journal of Pain 2006;10:287-333.

30. Präg P, Mills MC, Wittek R. Subjective socioeconomic status and health in cross-national comparison. Soc Sci Med 2016;149:84-92.

31. Hoebel J, Müters S, Kuntz B, et al. Messung des subjektiven sozialen Status in der Gesundheitsforschung mit einer deutschen Version der MacArthur Scale. Bundesgesundheitsblatt Gesundheitsforschung Gesundheitsschutz 2015;58:749-57. 